\title{
Perancangan Sistem Kontrol Sinkronisasi Kecepatan Conveyor Feeding Dengan Kecepatan Calender Berbasis Inverter di Mesin Calender Plant R
}

\author{
Muhamad Sodik Muttaqin ${ }^{1^{*}}$, Puguh Elmiawan ${ }^{2}$ \\ ${ }^{1^{*}}$ Teknik Elektronika, Politeknik Gajah Tunggal; muhamadsodikmuttaqin@gmail.com \\ ${ }^{2}$ Teknik Mesin, Politeknik Gajah Tunggal; elmiawan@poltek-gt.ac.id
}

\begin{abstract}
Abstrak: Proses calendering adalah proses pelapisan kawat baja (steel cord) dengan karet (compound) menjadi steel treatment sebagai salah satu material penyusun dalam proses pembuatan ban. Pada proses produksi steel treatment di Plant R PT ACR tentu tidak lepas dari adanya produk cacat. Metode penelitian yang digunakan adalah metode kuantitatif, peneliti mendapatkan cacat produk seperti supply compound kurang dan compound steel treatment lebih. Pada periode Desember 2020 sampai Februari 2021 frekuensi terjadinya kedua cacat produk tersebut sebanyak 254 kasus untuk supply compound kurang dan 147 kasus untuk compound steel treatment lebih. Penyebab utama kedua cacat produk disebabkan oleh faktor tidak sinkronnya kecepatan conveyor feeding yang men-supply compound ke mesin calender dengan kecepatan mesin calender. Dengan melakukan pengukuran kecepatan secara langsung terdapat selisih yang cukup jauh. Hal tersebut mengakibatkan supply compound menjadi kurang atau lebih. Dengan permasalahan tersebut maka akan dibuat perancangan sistem kontrol yang dapat mensinkronkan kecepatan conveyor feeding agar sesuai dengan kecepatan mesin calender dengan menggunakan inverter sebagai pengendali motornya. Hasil penelitian ini dinyatakan dalam bentuk tabel yang menunjukan hasil perhitungan untuk memperoleh nilai frekuensi yang dibutuhkan oleh motor induksi mencapai kecepatan yang diharapkan serta pengujian rangkaian.
\end{abstract}

Kata kunci: Calender, Sinkronisasi, Inverter, Frekuensi, Motor Induksi, Kecepatan

\section{Pendahuluan}

Ban merupakan salah satu bagian terpenting untuk sebuah kendaraan darat. Ban berfungsi untuk menyangga beban dari muatan serta sebagai peredam getaran yang dihasilkan dari dampak (impact) jalanan. Selain itu ban memberikan daya dorong serta pengereman pada kendaraan dan juga mengontrol arah kendaraan. [1]

Dalam konstruksi ban, material penyusun yang menjadi penguat dalam kekokohan ban adalah steel belt dan carcass. Steel belt merupakan komponen ban yang mengelilingi ban diantara carcass dengan tread (telapak ban) dan berfungsi untuk membantu menahan dari dampak (impact) jalan, sebagai stabilitas serta meningkatkan high speed performance. Sedangkan carcass atau dapat disebut sebagai tulang ban merupakan kerangka ban yang melingkari ban sehingga lapisan lain dapat diletakkan. Carcass berfungsi menjaga tekanan udara dibawah kontrol, menghubungkan tread dengan bead dan menstabilkan geometri ban. 


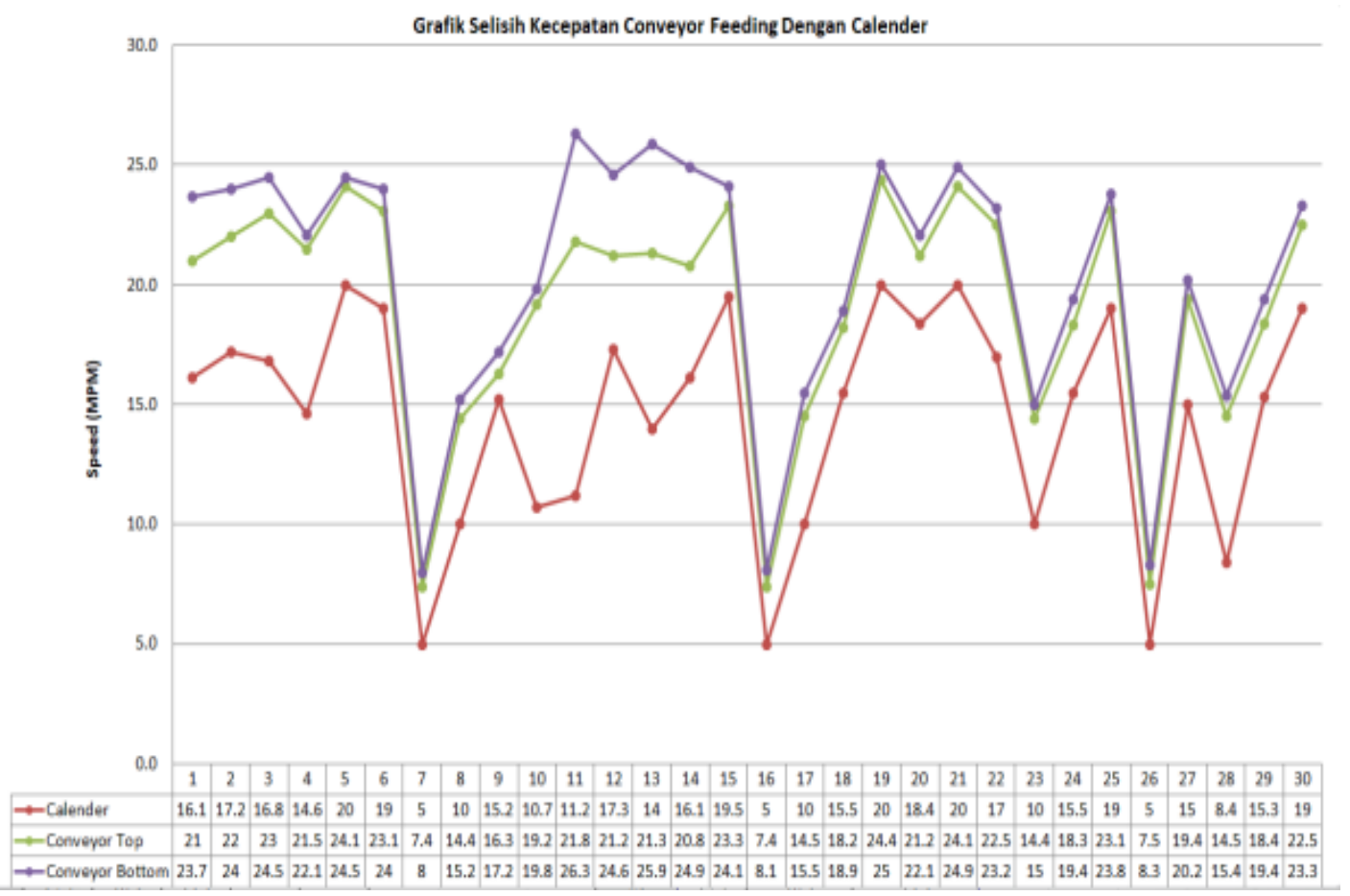

Gambar 1 Pengukuran Aktual Kecepatan Conveyor Feeding Dengan Kecepatan Calender

Terdapat beberapa jenis scrap dengan frekuensi berbeda yang terjadi pada proses produksi treatment selama periode desember 2020 sampai Februari 2021. Pada penelitian ini akan mengangkat dua jenis scrap yaitu supply compound kurang dan compound steel treatment lebih. Dalam jangka waktu 3 bulan terakhir (Desember 2020-Februari 2021) frekuensi terjadinya supply compound kurang sebanyak 254 kali dan frekuensi compound steel treatment lebih sebanyak 147 kali. Hal tersebut dapat dipengaruhi oleh faktor mesin yang menyebabkan speed conveyor feeding tidak sinkron dengan speed calender. Hal ini dapat memicu supply compound terputus jika speed calender lebih cepat dari speed conveyor feeding dan mengakibatkan compound kurang (under). Sebalikanya jika speed calender lebih rendah dari speed conveyor feeding menyebabkan compound menempel pada treatment dikarenakan compound lebih (over).

Berdasarkan gambar 1, setelah dilakukan pengambilan data sebanyak 30 kali menunjukan selisih kecepatan antara conveyor feeding dengan calender. Hal ini membuktikan bahwa tidak sinkronnya conveyor feeding dengan calender dimana conveyor feeding lebih cepat dari calender.

\section{Material}

\subsection{Programmable Logic Controller (PLC) Q Series}

PLC adalah sebuah peralatan yang berbasis microprocessor yang berisi kontrol yang mempunyai jenis dan level yang kompleksitas. PLC dirancang untuk menggantikan rangkaian relay dalam suatu sistem kontrol. PLC dapat diprogram dan dapat dikendalikan atau dioperasikan oleh pengguna yang tidak memiliki pengetahuan dibidang komputer secara khusus. [2]

PLC dapat menerima sinyal input yang berasal dari peralatan diskrit (on/off) dan peralatan analog (sensor).Sinyal input tersebut akan diidentifikasi oleh modul input dan akan diubah kedalam bentuk tegangan yang sesuai dan akan dikirim ke CPU. Setelah itu sinyal input akan diolah dan 
akan dikirim ke modul output berdasarkan program yang telah disimpan di CPU. Selama menjalankan proses, CPU PLC melakukan tiga operasi utama, yaitu :

1. Membaca data masukan melalui modul input.

2. Menjalankan program yang telah dibuat dan disimpan pada memori.

3. Mengupdate data-data paa modul output PLC.

\subsection{Software MELSOFT Mitsubishi GX-Developer}

Software GX-Work2 digunakan untuk membuat program PLC Mitsubishi dengan ladder diagram sebagai bahasa pemrogramannya. GX-Work mengenal symbol untuk perintah dalam pemrogramannya yaitu, input $(\mathrm{X})$, output $(\mathrm{Y})$, pewaktu / timer $(\mathrm{T})$, penghitung / counter (C). Software GX-Developer seperti bahasa pemrograman PLC dapat mengeksekusi perintah-perintah dasar dengan simbol kontak Normally Open (NO), Normally Close (NC), Coil Control, Bracket Control, invert. Lalu perintah logika dasar AND, OR, SET, RESET, dan PULSE, Timer, Counter dan yang lainnya. [3]

\subsection{Inverter Siemens Micromaster 440}

Micromaster 440 merupakan produk Siemens. Inverter ini menggunakan sumber tegangan 1 phasa sebesar $220-240 \mathrm{~V}$ dan tegangan 3 phasa sebesar $380-400$ Volt dengan frekuensi sebesar 50 $\mathrm{Hz}$ yang akan diubah menjadi tegangan AC 3 phasa dengan frekuensi dan tegangan yag variabel. Dimana frekuensi yang dikeluarkan mulai dari 5 - $50 \mathrm{~Hz}$ dan kapasitas daya sebesar 0,12 kW - 250 $\mathrm{kW}$.

\subsection{Motor Induksi}

Motor induksi merupakan salah satu aktuator yang berfungsi mengubah energi listrik menjadi energi gerak. Motor listrik dapat digolongkan kedalam dua jenis yaitu motor DC dan motor AC, sesuai dengan jenis daya yang disuplai. Motor AC lebih menguntungkan dibandingkan dengan motor DC. Karena motor AC lebih kecil, handal dan harganya tidak terlalu mahal. Namun kecepatan motor AC tidak dapat diatur atau tetap sesuai dengan frekuensi jala-jalanya. Sebaliknya motor DC laju, arah putar dan kecepatannya dapat diatur sesuai keinginan pengguna. Selain itu motor DC dapat digerakan dengan tegangan DC [4].

Untuk menghitung kecepatan motor induksi dapat menggunakan perhitungan seperti persamaan (1), dimana $n$ adalah Putaran per menit (RPM), $f$ adalah Frekuensi (Hz), dan $p$ adalah Jumlah kutub (Pole).

$$
n=\frac{120 . f}{p}
$$

\subsection{Kecepatan Linear Dan Kecepatan Sudut}

Kecepatan linear atau disebut juga kecepatan tangensial adalah hubungan antara panjang lintasan suatu benda melingkar dengan waktu yang ditempuh benda perselang waktu tempuhnya. Suatu benda membutuhkan waktu untuk menempuh satu putaran penuh disebut sebagai periodenya maka benda tersebut sudah menempuh satu keliling lingkaran. [4] 


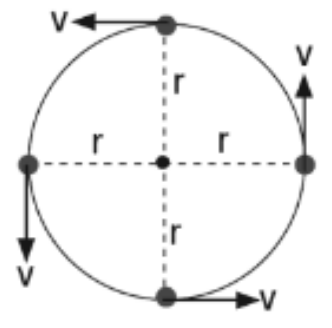

Gambar 2 Ilustrasi Kecepatan Linear [4]

Menghitung kecepatan linear dapat menggunakan persamaan (2)

$$
\mathrm{V}=\frac{2 \pi r}{T} \text { atau } \mathrm{V}=2 \pi r f
$$

Dimana $V$ adalah Kecepatan Linear $(\mathrm{m} / \mathrm{s}), \mathrm{r}$ adalah Jari-jari lintasan $(\mathrm{m}), \pi$ adalah Konstanta, $T$ adalah Periode (detik), dan $f$ adalah Frekuensi (putaran/detik). Kecepatan sudut atau disebut juga kecepatan angular adalah besar sudut yang ditempuh setiap satu satuan waktu [4].

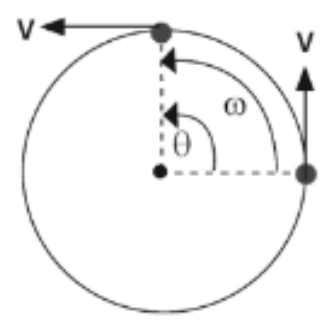

Gambar 3 Ilustrasi Kecepatan Sudut [4]

Menghitung kecepatan sudut dapat menggunakan persamaan (3)

$$
\omega=\frac{2 \pi}{T} \quad \text { atau atau } \omega=2 \pi f
$$

Dimana $\omega$ adalah $=$ Kecepatan sudut $(\mathrm{rad} / \mathrm{s}), \pi$ adalah Konstanta, $\mathrm{T}$ adalah Periode (detik), f adalah Frekuensi (putaran/detik). Mendapatkan kecepatan putaran (RPM) dari nilai kecepatan sudut (rad/s) dapat digunakan persamaan (4) dimana N adalah Kecepatan Putaran Per Menit (RPM)

$$
\omega=\frac{2 \pi N}{60}
$$

\subsection{Gear Box}

Gear box atau disebut dengan porsneling merupakan bagian pendukung dari motor induksi berupa roda gigi yang dapat menghantarkan tenaga mekanis dari motor induksi dengan kecepatan yang lebih rendah namun gaya putar lebih tinggi [5].

Adanya perbedaan kecepatan antara output shaft motor induksi dengan kecepatan yang dihasilkan oleh output shaft gear box. Sehingga dapat digunakan persamaan (5) sebagai berikut: 


$$
N 1=N 2 x i
$$

Dimana $N 1$ adalah putaran poros 1 (motor), $N 2$ adalah putaran poros 2 (gear box), dan $i$ adalah rasio gear box

\section{Metode Penelitian}

Metode penelitian yang digunakan dalam penelitian ini adalah metode kuantitatif dengan menggunakan data primer hasil pengukuran dan perhitungan. Hasil pengukuran dan perhitungan ditampilkan dalam bentuk tabel. Pengukuran meliputi selisih antara kecepatan conveyor feeding dengan calender dan ukuran dimensi roll pada objek yang akan diteliti. Sedangkan perhitungan meliputi frekuensi (1), kecepatan linear (2), kecepatan sudut (3), RPM (4), dan rasio gearbox (5).

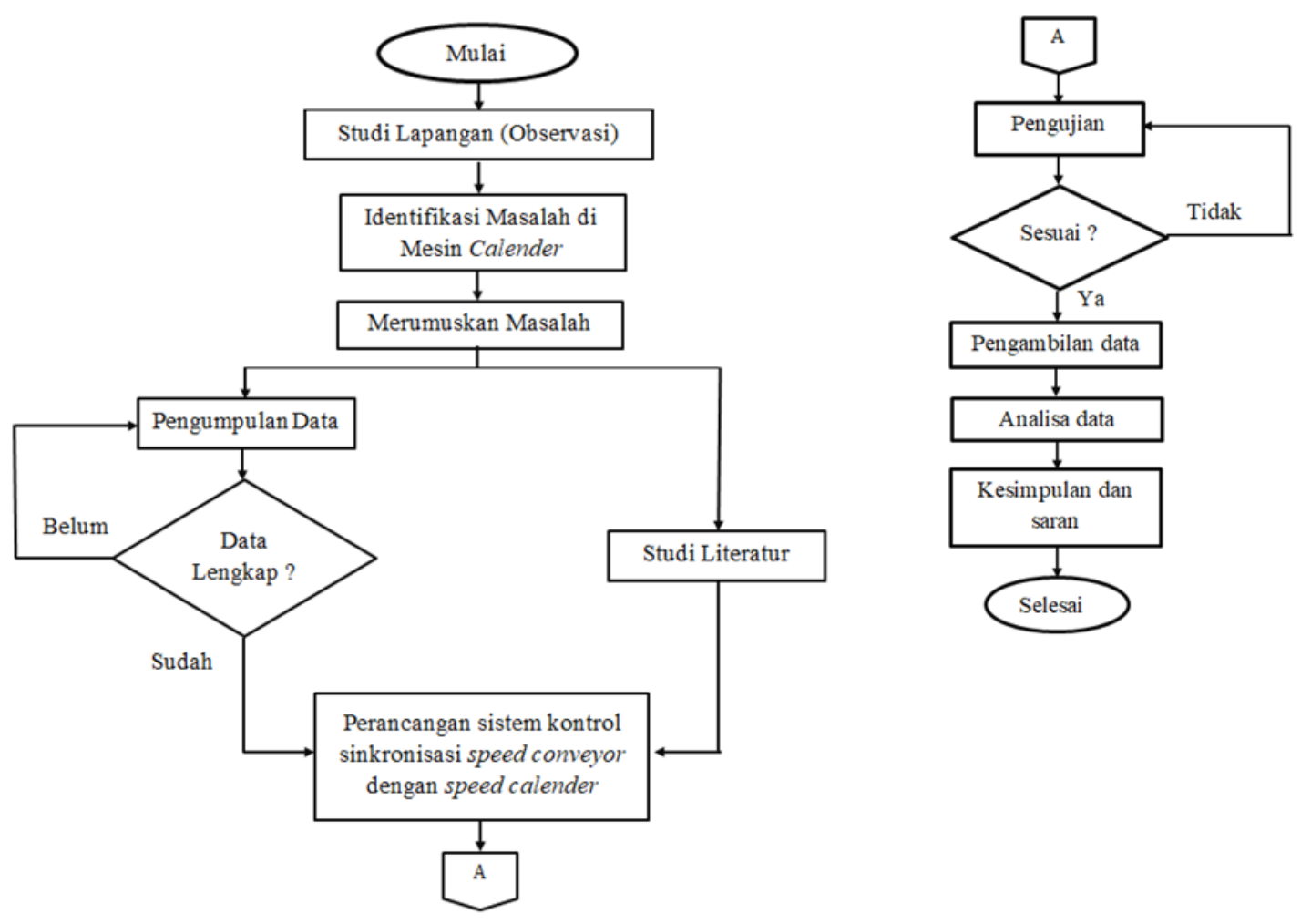

Gambar 4 Alur Pengerjaan Penelitian

a. Studi Lapangan (Observasi) : Studi lapangan merupakan tahap awal penelitian yang bertujuan mengetahui secara langsung kondisi lapangan untuk mencari informasi terkait lapangan kerja yang ingin diteliti serta menganalisa permasalahan dilapangan untuk diteliti.

b. Identifikasi masalah Di Mesin Calender : Pada tahap ini dilakukan identifikasi terhadap masalah yang diteliti, yaitu penyebab scrap treatment berupa supply compound kurang dan compound steel treatment lebih.

c. Merumusan masalah : Tahap ini bertujuan untuk menyusun rumusan masalah penyebab scrap treatment berupa supply compound kurang dan compound steel treatment lebih.

d. Pengumpulan Data : Tahap ini mencari data yang dapat membantu proses penelitian dan memperkuat latar belakang permasalahan.

e. Studi literatur : Studi literatur dilaksanakan untuk mempelajari dan memahami serta mencari informasi dan referensi yang terkait dengan permasalahan yang diteliti baik dalam bentuk buku, 
jurnal, artikel dan sebagainya.

f. Perancangan Sistem Kontrol PLC : Pada tahap ini dilakukan perancangan dan gambaran untuk memperbaiki masalah yang terjadi dengan membuat sistem kontrol sinkronisasi speed conveyor feeding dengan speed calender.

g. Pengujian : Sistem kontrol sinkronisasi speed yang telah dibangun kemudian diuji apakah bekerja dengan baik dan sesuai yang diharapkan atau tidak.

h. Pengambilan data : Setelah sistem kontrol berhasil berjalan dengan baik, maka dilakukanlah pengambilan data baik berupa sampel maupun populasi.

i. Analisa data : Data yang telah didapatkan kemudian diolah untuk dianalisa dan ditarik kesimpulannya.

\section{Hasil Penelitian dan Pembahasan}

\subsection{Perancangan Sistem Kontrol}

Sistem kontrol ini merupakan sistem kontrol close loop atau loop tertutup, dimana sistem ini bekerja secara berulang - ulang dengan pengontrolan kerja sistem dilakukan oleh PLC. PLC menjadi kontroler pada sistem ini dengan komponen input dan output. Komponen input hanya sebuah HMI yang digunakan sebagai pengganti push button fisik sehingga semua kontrol yang terhubung ke PLC dapat dikendalikan melalui layar HMI. Kemudian pada komponen output berupa inverter yang memproses frekuensi untuk mengatur kecepatan putaran motor induksi.

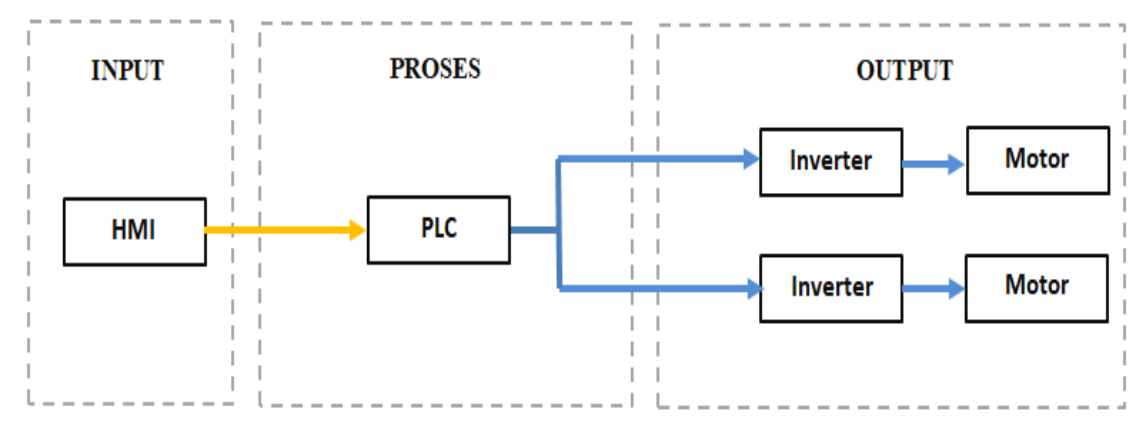

Gambar 5 Perancangan Sistem Kontrol

\subsection{Wiring Diagram Output Module PLC}

Perancangan ini menggunakan output modul QY10 yang terletak pada slot 3. Pada COM QY10 mampu diberi sumber tegangan AC 100/200 VAC maupun DC 24 VDC. Output modul QY10 terhubung dengan relay 24 VDC sebagai penghubung dan pemutus arus listrik dengan beban PLC yang akan terpasang pada pin terminal. 


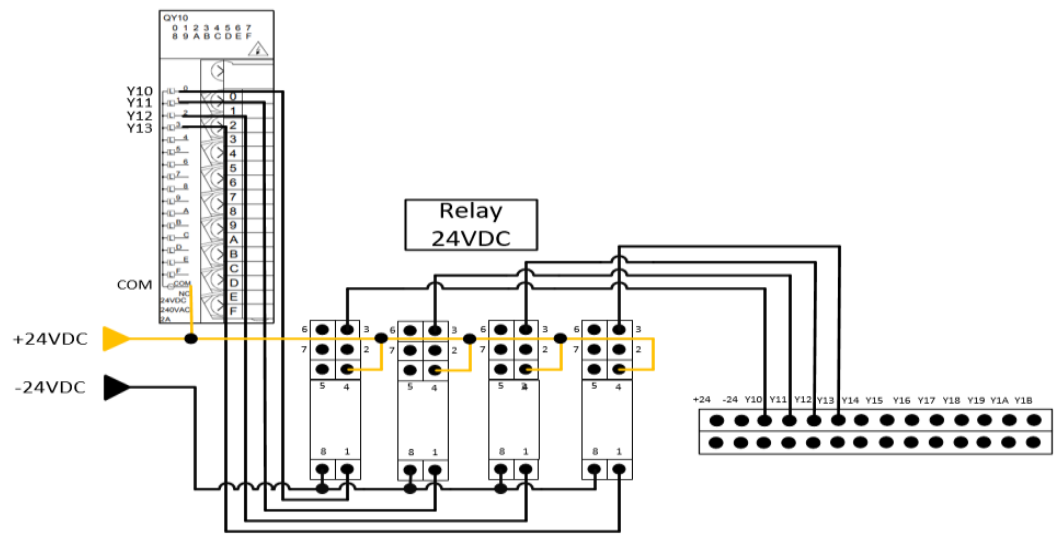

Gambar 6 Wiring Diagram Output Modul QY10

\subsection{Wiring Diagram Inverter}

Pengkabelan 2 unit inverter kepada PLC dilakukan secara parallel untuk menghemat penggunaan output PLC. Terminal output PLC Y10 terhubung parallel dengan terminal 5 inverter. Terminal output PLC Y11 terhubung parallel dengan terminal 8 inverter. Terminal output PLC Y12 terhubung parallel dengan terminal 16 inverter. Dan terminal output PLC Y13 terhubung parallel dengan terminal 17 inverter. Terminal sumber inverter L1 dan L2 terhubung dengan sumber PLN $220 \mathrm{VAC}$.

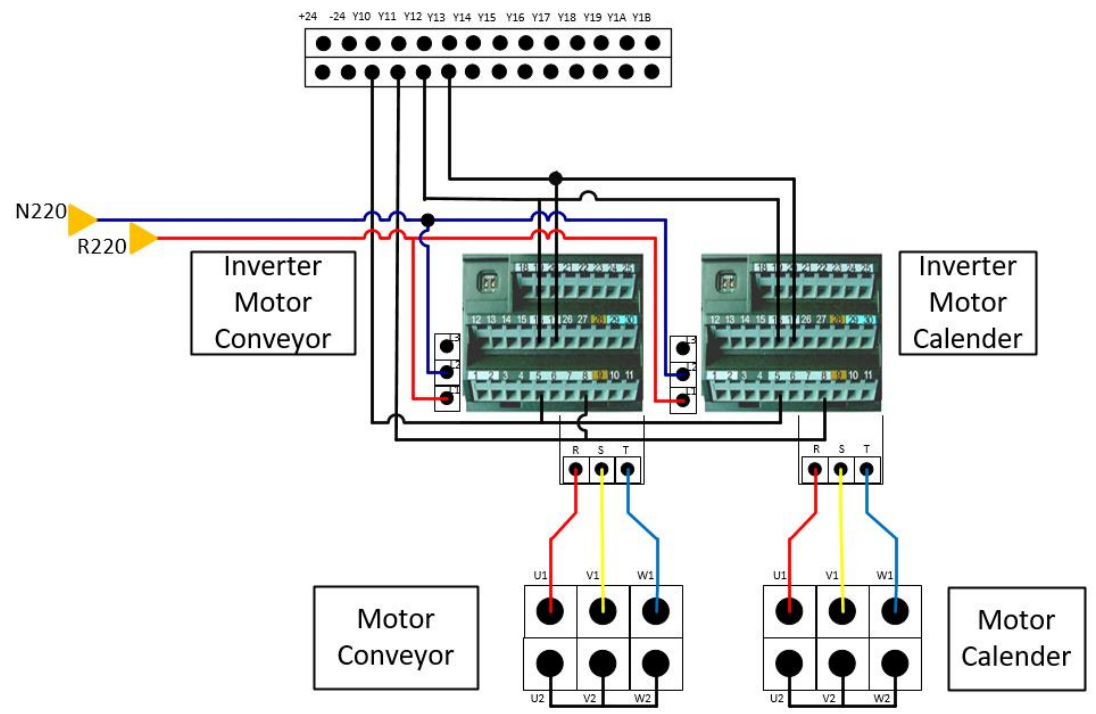

Gambar 7 Wiring Diagram Inverter

Masing-masing motor induksi terhubung dengan terminal R, S, T pada inverter. U1 terhubung dengan terminal R, V1 terhubung dengan terminal $S$ dan W1 terhubung dengan terminal T. Pada wiring motor induksi ini menggunakan rangkaian Star (bintang) sehingga terminal motor U2, V2 dan W2 terhubung secara seri seperti pada gambar.

\subsection{Pengalamatan Ladder Diagram PLC}

Berikut pengalamatan yang digunakan pada ladder diagram untuk sistem sinkronisasi speed conveyor feeding dengan speed calender. 
Tabel 1 Pengalamatan Ladder Diagram PLC

\begin{tabular}{cll}
\hline No & \multicolumn{1}{c}{ Alamat } & \multicolumn{1}{c}{ Keterangan } \\
\hline 1 & M0 & HMI Button Stop Inverter $(0 \mathrm{mpm})$ \\
2 & M1 & HMI Button Speed 5 mpm \\
3 & M2 & HMI Button Speed 10 mpm \\
4 & M3 & HMI Button Speed 15 mpm \\
5 & M4 & HMI Button Speed 20 mpm \\
6 & M5 & HMI Button Speed 25 mpm \\
7 & SM400 & Always On \\
8 & Y10 & Terminal 5 Inverter \\
9 & Y11 & Terminal 8 Inverter \\
10 & Y12 & Terminal 16 Inverter \\
11 & Y13 & Terminal 17 Inverter \\
\hline
\end{tabular}

4.5 Perhitungan Frekuensi Motor Induksi

Mendapatkan nilai frekuensi yang dibutuhkan oleh motor induksi calender dan conveyor feeding dibutuhkan spesifikasi yang terdapat pada tabel 3 untuk melengkapi proses perhitungan.

Tabel 2 Spesifikasi Item

\begin{tabular}{lccc}
\hline \multicolumn{1}{c}{ Item } & Calender & Conveyor & Satuan \\
\hline Jumlah kutub motor & 4 & 6 & Pole \\
\hline Frequency & 50 & 50 & $\mathrm{~Hz}$ \\
\hline RPM & 1500 & 1000 & $\mathrm{rpm}$ \\
\hline Diameter roll & 610 & 50 & Millimeter \\
\hline Rasio gearbox & $74: 1$ & $2: 1$ & - \\
\hline
\end{tabular}

Terdapat lima variasi kecepatan dengan satuan Meter Per Menit (MPM) yaitu 5 MPM, 10 MPM, 15 MPM, 20 MPM dan 25 MPM. Pada bagian ini akan dijabarkan mengenai cara perhitungan untuk mendapatkan nilai frekuensi yang dibutuhkan oleh motor calender dan motor conveyor pada kecepatan putaran 25 MPM. Untuk mendapatkan nilai kecepatan sudut dapat digunakan persamaan (2) dengan mendapatkan nilai periode ( $\mathrm{T}$ ) terlebih dahulu, sehingga diperoleh $\mathrm{T}$ adalah 4,608 s. Masukan nilai T pada persamaan (3) untuk mendapatkan nilai kecepatan sudut, sehingga diperoleh $\omega=1,364 \mathrm{rad} / \mathrm{s}$.

Setelah diketahui nilai kecepatan sudut, maka nilai tersebut dapat digunakan untuk mencari nilai RPM pada shaft (output) gearbox dengan menggunakan persamaan (4). Sehingga $\mathrm{N}$ diperoleh 13,02 RPM. Nilai N yang didapat adalah nilai RPM pada shaft (output) gearbox (N2). Setelah itu dapat digunakan untuk menghitung nilai RPM pada shaft (input) motor calender (N1) dengan rasio (i) gearbox $74: 1$. Untuk mendapatkan nilai RPM N1 dapat digunakan persamaan (5). Hasil perhitungan diperoleh N1 adalah 963,48 RPM.

Setelah didapatkan nilai N1 sebagai kecepatan putaran pada shaft motor calender, selanjutnya dapat digunakan untuk menghitung nilai frekuensi yang dibutuhkan oleh motor untuk menghasilkan kecepatan putaran sebesar 963,48 RPM. Perhitungan dapat dilakukan dengan persamaan (1). Dari hasil perhitungan, maka didapatkan frekuensi sebesar 32,12 Hz untuk menghasilkan kecepatan putaran linear sebesar 25 MPM pada roll calender. Berikut hasil seluruh perhitungan untuk mendapatkan nilai frekuensi yang dibutuhkan oleh motor calender. 
Tabel 3 Perhitungan Frekuensi Motor Calender

\begin{tabular}{ccccccc}
\hline $\mathbf{M P M}$ & $\begin{array}{c}\mathbf{V} \\
\mathbf{( m / s )}\end{array}$ & $\mathbf{T}(\mathbf{s})$ & $\begin{array}{c}\boldsymbol{\omega} \\
(\mathbf{r a d} / \mathbf{s})\end{array}$ & $\begin{array}{c}\mathbf{N} \\
\mathbf{R p m})\end{array}$ & $\begin{array}{c}\mathbf{N 1} \\
(\mathbf{R p m})\end{array}$ & $\mathbf{f}(\mathbf{H z})$ \\
\hline 5 & 0.08 & 23.01 & 0.27 & 2.61 & 193.00 & 6.43 \\
10 & 0.17 & 11.50 & 0.55 & 5.22 & 385.99 & 12.87 \\
15 & 0.25 & 7.67 & 0.82 & 7.82 & 578.99 & 19.30 \\
20 & 0.33 & 5.75 & 1.09 & 10.43 & 771.98 & 25.73 \\
25 & 0.42 & 4.60 & 1.37 & 13.04 & 964.98 & 32.17 \\
\hline
\end{tabular}

Berikut hasil seluruh perhitungan untuk mendapatkan nilai frekuensi yang dibutuhkan oleh motor conveyor

Tabel 4 Perhitungan Frekuensi Motor Conveyor

\begin{tabular}{ccccccc}
\hline \multirow{2}{*}{$\mathbf{M P M}$} & $\begin{array}{c}\mathbf{V} \\
(\mathbf{m} / \mathbf{s})\end{array}$ & $\mathbf{T}(\mathbf{s})$ & $\begin{array}{c}\omega \\
(\mathbf{r a d} / \mathbf{s})\end{array}$ & $\begin{array}{c}\mathbf{N} \\
\mathbf{R} \mathbf{p m})\end{array}$ & $\begin{array}{c}\mathbf{N 1} \\
(\mathbf{R} \mathbf{p m})\end{array}$ & $\mathbf{f}(\mathbf{H z})$ \\
\hline 5 & 0.08 & 3.77 & 1.67 & 15.91 & 31.82 & 1.59 \\
10 & 0.17 & 1.89 & 3.33 & 31.82 & 63.64 & 3.18 \\
15 & 0.25 & 1.26 & 5.00 & 47.73 & 95.45 & 4.77 \\
20 & 0.33 & 0.94 & 6.67 & 63.64 & 127.27 & 6.36 \\
25 & 0.42 & 0.75 & 8.33 & 79.55 & 159.09 & 7.95 \\
\hline
\end{tabular}

Tabel 4 dan Tabel 5 menunjukan hasil perhitungan frekuensi (f) yang dibutuhkan oleh motor calender dan motor conveyor untuk mencapai kecepatan putaran (MPM) yang diinginkan. Berdasarkan hasil yang didapatkan, semakin besar kecepatan putaran (MPM) maka semakin besar frekuensi (f) yang dibutuhkan.

\subsection{Setting Parameter Inverter Micromaster 440}

Setting parameter inverter micromaster 440 ini digunakan untuk mengontrol kecepatan putaran motor induksi agar sesuai dengan kehendak yang diinginkan. Kecepatan putaran motor induksi dipengaruhi oleh besarnya frekuensi yang diberikan.

Tabel 5 Setting Parameter Inverter Micromaster 440

\begin{tabular}{clcc}
\hline Parameter & \multicolumn{1}{c}{ Deskripsi } & Calender & Conveyor \\
\hline P0003 & User Acces Level & 3 & 3 \\
P0004 & Parameter Filter & 0 & 0 \\
P0010 & Commisioning Parameter & 0 & 0 \\
P0700 & Selection of Command Source & 2 & 2 \\
P1000 & Selection of Frequency Set Point & 3 & 3 \\
P1004 & Frequency Set Point Terminal 8 & $4,3 \mathrm{~Hz}$ & $1,58 \mathrm{~Hz}$ \\
P1005 & Frequency Set Point Terminal 16 & $8,66 \mathrm{~Hz}$ & $3,17 \mathrm{~Hz}$ \\
P1006 & Frequency Set Point Terminal 17 & $17,3 \mathrm{~Hz}$ & $6,37 \mathrm{~Hz}$ \\
P1080 & Min Frequency & $0 \mathrm{~Hz}$ & $0 \mathrm{~Hz}$ \\
P1082 & Max Frequency & $50 \mathrm{~Hz}$ & $50 \mathrm{~Hz}$ \\
P1120 & Ramp Up Time & $10 \mathrm{sec}$ & $10 \mathrm{sec}$ \\
P1121 & Ramp Down Time & $10 \mathrm{sec}$ & $10 \mathrm{sec}$ \\
\hline
\end{tabular}


Setting parameter yang digunakan untuk mengontrol kecepatan putaran motor induksi untuk calender dan conveyor ditunjukan pada Tabel 6. P1004 diisi dengan nilai frekuensi untuk kecepatan 5 MPM. P1005 diisi dengan nilai frekuensi untuk kecepatan 10 MPM. P1005 diisi dengan nilai frekuensi untuk kecepatan 20 MPM. Sedangkan untuk menjalankan frekuensi untuk kecepatan 15 MPM dengan mengaktifkan P1004 dan P1005 dan untuk kecepatan 25 MPM mengaktfikan P1004 dengan P1006. 4.7 Ladder Diagram PLC.

Kumpulan program pada PLC Mitsubishi biasa disebut dengan ladder diagram. Pembuatan ladder diagram dilakukan menggunakan software MELSOFT GX-Works 2. Pada line 0 terdapat alamat SM400 yang terhubung dengan Y10. SM400 dipasang agar ketika PLC menyala maka SM400 akan langsung on memberikan trigger untuk menyalakan Y10. Y10 merupakan output PLC yang terhubung dengan terminal 5 pada inverter. Ketika terminal 5 inverter mendapatkan tegangan, maka inverter akan aktif atau keadaan ready.

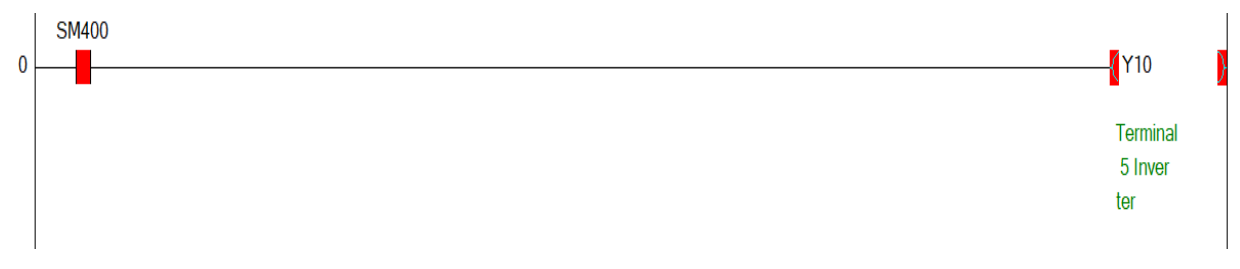

Gambar 8 Ladder Diagram Trigger Inverter

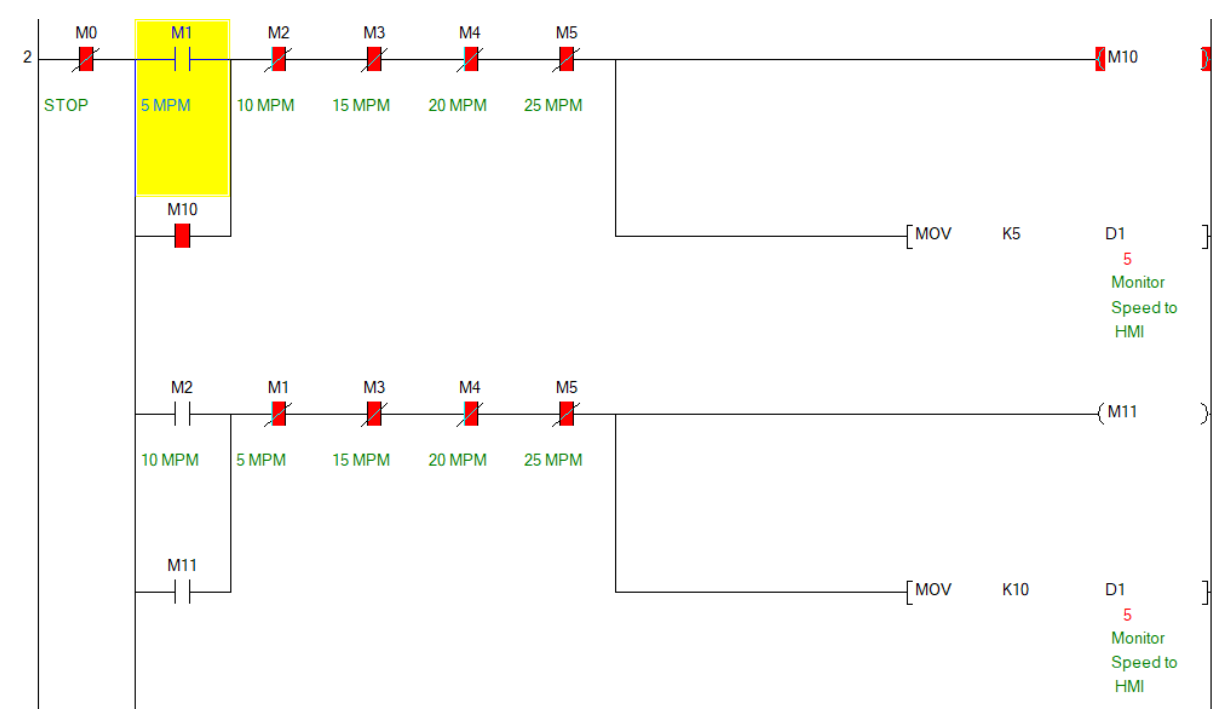

Gambar 9 Ladder Diagram Kontrol Variasi Kecepatan 5 MPM dan 10 MPM

Gambar 9 merupakan gambaran ladder diagram untuk mengontrol variasi kecepatan conveyor dan calender untuk kecepatan 5 MPM dan 10 MPM. Penggunaan internal relay (M) sebagai alamat buttton pada HMI untuk memilih variasi kecepatan yang diinginkan sesuai dengan device comment yang berada tepat dibawah ladder diagram. M1 untuk kecepatan 5 mpm, M2 untuk kecepatan 10 mpm, M3 untuk kecepatan 15 mpm, M4 untuk kecepatan 20 mpm dan M5 untuk kecepatan 25 mpm. Serta terdapat M0 yang digunakan sebagai button stop ataupun untuk mereset variasi kecepatan yang dipilih sebelumnya. 
M1 sampai M5 NO (normally Open) sebagai button pemilih variasi kecepatan, dan M1-M5 NC (normally close) sebagai pemutus ketika salah satu variasi kecepatan ditekan maka variasi kecepatan sebelumnya akan tidak aktif. Terdapat D1 ditiap masing-masing line variasi kecepatan, D1 digunakan untuk memberikan indikator pada layar HMI terhadap kecepatan yang sedang dijalankan. Dengan memanfaatkan MOV untuk merubah nilai D1 berdasarkan besarnya nilai K yang digunakan. Saat M1 ditekan maka akan memindahkan nilai K5 ke D1.

Saat M1 NO ditekan, maka akan mengaktifkan M10 yang akan mentrigger output PLC yang terhubung dengan relay 24VDC. Serta akan mengaktifkan MOV K5 D1 yang terhubung dengan tampilan HMI untuk menampilkan kecepatan yang sedang berjalan, maka akan menunjukan tampilan 5 MPM pada HMI. M2 NO bekerja serupa dengan M1 NO, namun M2 NO akan mengaktikan M11 dan mengubah tampilan HMI dengan menampilkan kecepatan 10 MPM, sesuai dengan nilai K yang terdapat pada MOV D1. Saat M2 NO ditekan, maka M2 NC akan memutus M10. Sama halnya dengan internal relay (M) NC lainnya.

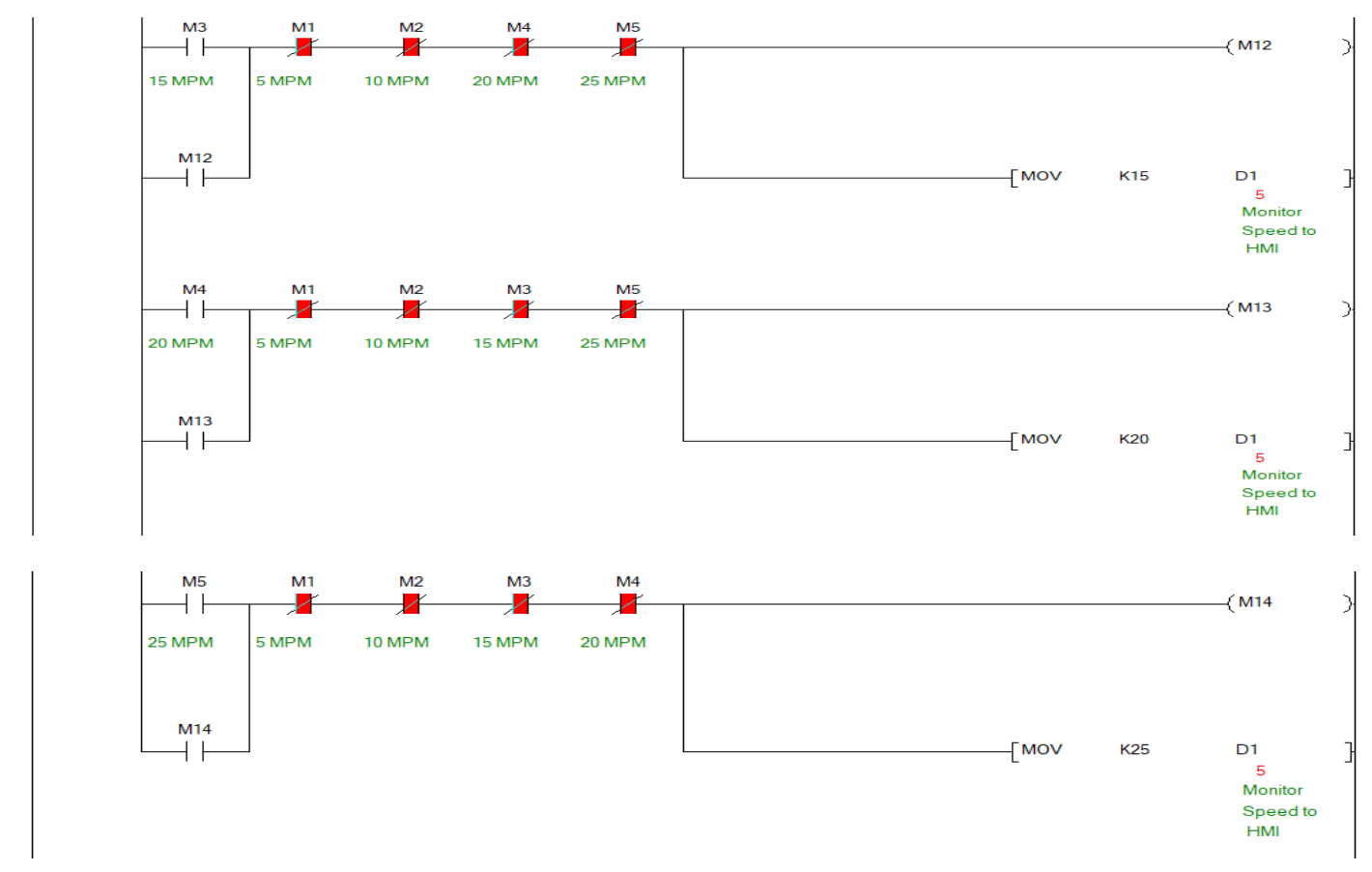

Gambar 10 Ladder Diagram Kontrol Variasi Kecepatan 15 MPM, 20 MPM dan 25 MPM

Sama hal nya dengan M1 dan M2 NO. M3, M4 dan M5 NO saat ditekan akan mengaktifkan internal relay yang terdapat pada ujung line masing-masing ladder. Begitupun dengan mengubah tampilan indikator pada HMI yang menunjukan kecepatan yang sedang dijalankan sesuai dengan nilai K yang tertera pada masing-masing line. M10 sampai M14 yang berada pada bagian depan ladder diagram sebagai trigger untu mengaktifkan Y11 sampai Y13 sesuai dengan internal relay yang aktif. Y11 sampai Y13 terhubung dengan terminal pada inverter yang memiliki variasi atau parameter kecepatan yang sudah di setting sebelumnya. Saat kecepatan $15 \mathrm{mpm}$ yang dijalankan, maka M12 akan mentrigger Y11 dan Y12 sehingga akan aktif secara bersamaan. Dengan aktifnya Y11 dan Y12 secara bersamaan, maka frekuensi yang sudah disetting pada terminal 8 dan terminal 16 akan dijumlahkan sehingga nilai frekuensinya dapat menggerakan motor dengan kecepatan 15 mpm. Sedangkan untuk speed $25 \mathrm{mpm}$ dengan menjumlahkan nilai frekuensi terminal 8 dan 17. 


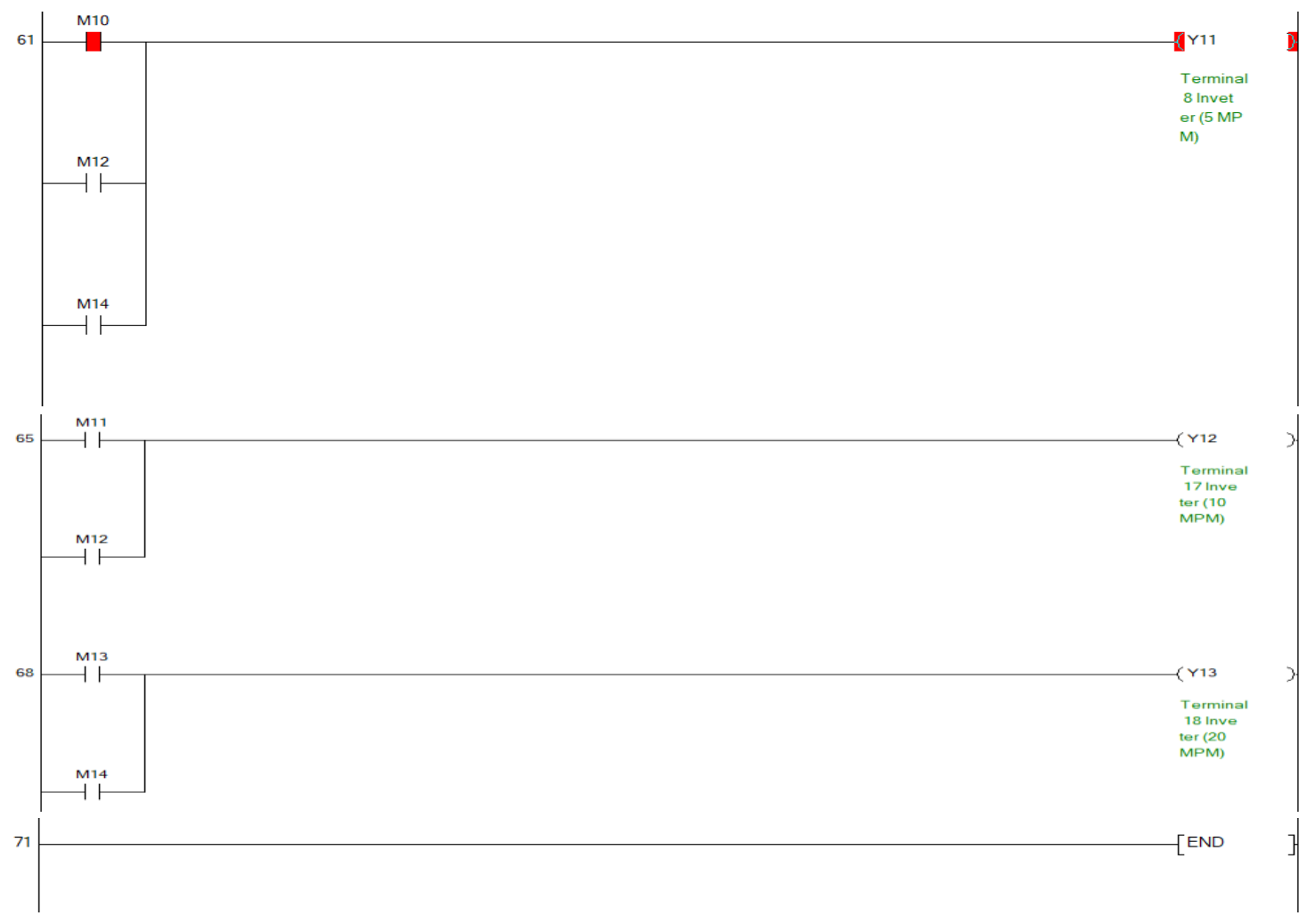

Gambar 11 Ladder Diagram Output Variasi Kecepatan

\subsection{Pengalamatan Laddder Diagram PLC}

Berikut pengalamatan yang digunakan pada ladder diagram untuk sistem sinkronisasi speed conveyor feeding dengan speed calender.

Tabel 6 Pengalamatan Ladder Diagram PLC

\begin{tabular}{lcl}
\hline No & Alamat & \multicolumn{1}{c}{ Keterangan } \\
\hline 1 & M0 & HMI Button Stop Inverter $(0 \mathrm{mpm})$ \\
2 & M1 & HMI Button Speed $5 \mathrm{mpm}$ \\
3 & M2 & HMI Button Speed $10 \mathrm{mpm}$ \\
4 & M3 & HMI Button Speed $15 \mathrm{mpm}$ \\
5 & M4 & HMI Button Speed $20 \mathrm{mpm}$ \\
6 & M5 & HMI Button Speed $25 \mathrm{mpm}$ \\
6 & SM400 & Always On \\
7 & Y10 & Terminal 5 Inverter \\
8 & Y11 & Terminal 8 Inverter \\
9 & Y12 & Terminal 16 Inverter \\
10 & Y13 & Terminal 17 Inverter \\
\hline
\end{tabular}

4.9 Verifikasi Program Sinkronisasi Speed Conveyor Feeding Dengan Speed Calender

Verifikasi program dilakukan dengan cara menjalankan program dan melakukan pengujian terhadap program tersebut. Verifikasi dilakukan dengan cara menguji program secara satu persatu pada ladder diagram GX-Work 2 dan dihubungkan dengan GT Designer 3, mulai dari menguji 
masukkan program hingga keluaran yang terdapat pada program. Hasil yang didapat setelah dilakukan verifikasi program dapat dilihat pada Tabel 8.

Tabel 7 Verifikasi Operasi Kerja Program

\begin{tabular}{|c|c|c|c|}
\hline No & Item & Cara Kerja & Keterangan \\
\hline 1 & M0 & $\begin{array}{l}\text { Saat ditekan maka akan memutus semua ladder } \\
\text { yang aktif. }\end{array}$ & Sesuai \\
\hline 2 & M1 & $\begin{array}{l}\text { a. Saat M1 NO ditekan akan mengaktifkan M10 } \\
\text { dan Y11. } \\
\text { b. Saat M1 NC ditekan akan memutus button } \\
\text { speed yang aktif. }\end{array}$ & Sesuai \\
\hline 3 & M2 & $\begin{array}{l}\text { a. Saat M2 NO ditekan akan mengaktifkan M11 } \\
\text { dan Y12. } \\
\text { b. Saat M2 NC ditekan akan memutus button } \\
\text { speed yang aktif. }\end{array}$ & Sesuai \\
\hline 4 & M3 & $\begin{array}{l}\text { a. Saat M3 NO ditekan akan mengaktifkan M12, } \\
\text { Y11 dan Y12. } \\
\text { b. Saat M3 NC ditekan akan memutus button } \\
\text { speed yang aktif. }\end{array}$ & Sesuai \\
\hline 5 & M4 & $\begin{array}{l}\text { a. Saat M4 NO ditekan akan mengaktifkan M13 } \\
\text { dan Y13. } \\
\text { b. Saat M4 NC ditekan akan memutus button } \\
\text { speed yang aktif. }\end{array}$ & Sesuai \\
\hline 6 & M5 & $\begin{array}{l}\text { a. Saat M5 NO ditekan akan mengaktifkan M14, } \\
\text { Y11 dan Y13. } \\
\text { b. Saat M5 NC ditekan akan memutus button } \\
\text { speed yang aktif. }\end{array}$ & Sesuai \\
\hline 7 & Y10 & Langsung aktif saat PLC dinyalakan. & Sesuai \\
\hline 8 & Y11 & Akan aktif ketika M10, M12 dan M14 aktif. & Sesuai \\
\hline 9 & Y12 & Akan aktif ketika M11 dan M12 aktif. & Sesuai \\
\hline 10 & Y13 & Akan aktif ketika M13 dan M14 aktif. & Sesuai \\
\hline
\end{tabular}

\subsection{Verifikasi Rangkaian}

Verifikasi rangkaian dilakukan dengan menguji masing-masing komponen apakah dapat bekerja susuai dengan kehendak atau tidak.. Verifikasi dilakukan dengan cara menjalankan program satu persatu. Program dijalankan dengan menghubungkan PLC dengan komponen lainnya yang akan dikontrol. Tabel-tabel berikut merupakan hasil yang diperoleh dari verifikasi.

Tabel 8 Verifikasi Operasi Kerja Relay PLC

\begin{tabular}{ccc}
\hline No & Relay & Keterangan \\
\hline 1 & Y10 & Relay aktif \\
2 & Y11 & Relay aktif \\
3 & Y12 & Relay aktif \\
4 & Y13 & Relay aktif \\
\hline
\end{tabular}


Berdasarkan tabel 8, terminal output relay PLC berhasil aktif sesuai dengan program yang dijalankan. Aktifnya relay ditandai dengan menyalanya lampu indikator yang berada pada relay.

Tabel 9 Verifikasi Operasi Kerja Inverter

\begin{tabular}{clcc}
\hline No & \multicolumn{1}{c}{ Terminal } & Keterangan & $\begin{array}{c}\text { Tampilan } \\
\text { LCD }\end{array}$ \\
\hline 1 & Terminal 5 inverter motor calender & Aktif & - \\
2 & Terminal 8 inverter motor calender & Aktif & $4,30 \mathrm{~Hz}$ \\
3 & Terminal 16 inverter motor calender & Aktif & $8,66 \mathrm{~Hz}$ \\
4 & Terminal 17 inverter motor calender & Aktif & $17,30 \mathrm{~Hz}$ \\
5 & Terminal 5 inverter motor conveyor & Aktif & - \\
6 & Terminal 8 inverter motor conveyor & Aktif & $1,58 \mathrm{~Hz}$ \\
7 & Terminal 16 inverter motor conveyor & Aktif & $3,17 \mathrm{~Hz}$ \\
8 & Terminal 17 inverter motor conveyor & Aktif & $6,37 \mathrm{~Hz}$ \\
\hline
\end{tabular}

Verifikasi inverter dilakukan dengan mengaktifkan masing-masing terminal yang terhubung dengan output PLC. Kemudian melihat tampilan layar inverter yang menunjukkan nilai frekuensi yang sedang dijalankan sesuai atau tidak dengan program yang sedang aktif.

Tabel 10 Verifikasi Motor Induksi

\begin{tabular}{cll}
\hline No & \multicolumn{1}{c}{ Terminal } & Keterangan \\
\hline 1 & Motor Induksi Calender & Berputar \\
2 & Motor Induksi Conveyor & Berputar \\
\hline
\end{tabular}

Verifkasi motor induksi dilakukan dengan memperhatikan apakah motor berputar sesuai dengan program yang dijalankan.

\section{Kesimpulan}

Perancangan sistem kontrol sinkronisasi speed conveyor feeding dengan speed calender telah berhasil dengan menggunakan PLC Mitsubishi Q series sebagai sistem kontrol dan inverter siemens micromaster 440 sebagai pengendali kecepatan putaran motor induksi conveyor feeding dan calender.

\section{Referensi}

1. A. L. Sutarto, “Analisa Pengaruh Distribusi Berat Terhadap Pemakaian Ban Pada Honda Beat Fi," vol. 01, no. 03, pp. 4-15, 2016.

2. D. Yuhendri, "Penggunaan PLC Sebagai Pengontrol Peralatan Building Automatis," J. Electr. Technol., vol. 3, no. 3, pp. 121-127, 2018.

3. A. Mubyarto, W. Hp, A. Taryana, and M. Munawar, "The Application of Industrial Prototype Conveyor System Developed By PLC Mitsubishi FX2N Priswanto , Agung Mubyarto, Widhiatmoko HP , Acep Tary," Techno, vol. 18, no. 1, pp. 7-14, 2017.

4. H. Saptomo, G. E. Pranomo, and H. Al Khindi, “Analisa Daya Dan Kontrol Kecepatan Motor Pada Alat Bantu Las Rotary Positioner Table," Jurnal Tek. Mesin Fak. Tek. Univ. Ibn Khaldun 
Bogor, vol. 1, p. 33, 2017.

5. D. I. M. Yamin and W. Purwoko, "Perencanaan Gear Box Dan Analisis Statik Rangka Conveyor Menggunakan Sofware Catia V5," Perenc. Gear Box Dan Anal. Statik Rangka Conveyor Menggunakan Sofware Catia V5, pp. 1-26, 2017.

(C) 2021 oleh penulis. Dikirim untuk kemungkinan publikasi akses terbuka di bawah syarat dan ketentuan lisensi Creative Commons Attribution (CC BY) (http://creativecommons.org/licenses/by/4.0/). 
Complete 2021, Vol. 1, No. 1, doi.org/10.52435/complete.v1i1.96 